\title{
Identifying the novel key genes in renal cell carcinoma by bioinformatics analysis and cell experiments
}

\author{
Yeda Chen ${ }^{1 \dagger}$, Di Gu${ }^{1 \dagger}$, Yaoan Wen ${ }^{1 \dagger}$, Shuxin Yang ${ }^{1}$, Xiaolu Duan ${ }^{1}$, Yongchang Lai ${ }^{1}$, Jianan Yang ${ }^{2}$, \\ Daozhang Yuan², Aisha Khan³ ${ }^{3}$ Wenqi Wu ${ }^{1}$ and Guohua Zeng ${ }^{1 *}$ (D)
}

\begin{abstract}
Background: Although major driver gene have been identified, the complex molecular heterogeneity of renal cell cancer (RCC) remains unclear. Therefore, more relevant genes need to be identified to explain the pathogenesis of renal cancer.

Methods: Microarray datasets GSE781, GSE6344, GSE53000 and GSE68417 were downloaded from Gene Expression Omnibus (GEO) database. The differentially expressed genes (DEGs) were identified by employing GEO2R tool, and function enrichment analyses were performed by using DAVID. The protein-protein interaction network (PPI) was constructed and the module analysis was performed using STRING and Cytoscape. Survival analysis was performed using GEPIA. Differential expression was verified in Oncomine. Cell experiments (cell viability assays, transwell migration and invasion assays, wound healing assay, flow cytometry) were utilized to verify the roles of the hub genes on the proliferation of kidney cancer cells (A498 and OSRC-2 cell lines).

Results: A total of 215 DEGs were identified from four datasets. Six hub gene (SUCLG1, PCK2, GLDC, SLC12A1, ATP1A1, PDHA1) were identified and the overall survival time of patients with RCC were significantly shorter. The expression levels of these six genes were significantly decreased in six RCC cell lines(A498, OSRC-2, 786- O, Caki-1, ACHN, 769-P) compared to 293t cell line. The expression level of both mRNA and protein of these genes were downregulated in RCC samples compared to those in paracancerous normal tissues. Cell viability assays showed that overexpressions of SUCLG1, PCK2, GLDC significantly decreased proliferation of RCC. Transwell migration, invasion, wound healing assay showed overexpression of three genes(SUCLG1, PCK2, GLDC) significantly inhibited the migration, invasion of RCC. Flow cytometry analysis showed that overexpression of three genes(SUCLG1, PCK2, GLDC) induced G1/S/ G2 phase arrest of RCC cells.
\end{abstract}

Conclusion: Based on our current findings, it is concluded that SUCLG1, PCK2, GLDC may serve as a potential prognostic marker of RCC.

${ }^{\dagger}$ Yeda Chen, Di Gu and Yaoan Wen contribute equally to this work

*Correspondence: gzgyzgh@vip.tom.com

${ }^{1}$ Department of Urology, Minimally Invasive Surgery Center, The First Affiliated Hospital of Guangzhou Medical University, Guangdong Key Laboratory of Urology, Kangda Road 1\#, Haizhu District, Guangzhou 510230, Guangdong, China

Full list of author information is available at the end of the article

\section{Background}

Renal cell carcinoma (RCC) is a common malignant tumor of the urinary system [1] with the main treatment being surgical resection. The prognosis of metastatic renal cell carcinoma is poor because it is not sensitive to chemotherapy or other form of treatment and has a 5 - year survival rate which is less than 5\% [2]. Although many studies have shown that the most common causes otherwise in a credit line to the material. If material is not included in the article's Creative Commons licence and your intended use is not permitted by statutory regulation or exceeds the permitted use, you will need to obtain permission directly from the copyright holder. To view a copy of this licence, visit http://creativecommons.org/licenses/by/4.0/. The Creative Commons Public Domain Dedication waiver (http://creativecommons.org/publicdomain/zero/1.0/) applies to the data made available in this article, unless otherwise stated in a credit line to the data. 
of RCC are genetic factors, lifestyle, genetic mutations, cell damage, etc., the pathogenesis of renal cancer is extremely complicated, and the current research has not yet been fully elucidated. Therefore, potential markers for efficient diagnosis and treatment are urgently needed. Microarray technology has enabled us to explore genetic alterations in RCC and has proven to be a useful method for identifying new biomarkers in diseases.

There is an increasing evidence of the abnormal expression of genes being involved in the development and progression of RCC. It has been reported that Solute carrier family 12 member 1 (SLC12A1), Sodium/potassium-transporting ATPase subunit alpha-1 (ATP1A1) and Pyruvate dehydrogenase E1 component subunit alpha (PDHA1) are differentially expressed in renal cancer tissues. These are closely linked to the occurrence and development of renal cancer [3-5]. The Cancer Genome Atlas (TCGA) database found that Succinate CoA ligase subunit alpha (SUCLG1), Phosphoenolpyruvate carboxykinase (PCK2) and Glycine dehydrogenase (GLDC) were differentially expressed in renal cancer, however, there is no scientific research that showed whether they are the oncogenic molecules in renal cancer. Therefore, this project investigated these three molecules to clarify their mechanism of action in renal cancer.

So far, for RCC patients, no clear and effective molecular marker has been found for the diagnosis or treatment of RCC. Molecular markers help to improve early diagnosis, predict prognosis, and guide the development of treatment plans for patients with RCC. With the advent of the concept of individualized treatment of tumors and the advent of precision medicine, we should continue to explore new molecular markers or possible molecules of RCC Marker combinations, with a view to discovering molecular markers or combinations thereof that can accurately diagnose or predict the prognosis of RCC.

Over the past few decades, microarray technology and bioinformatics analysis have been widely used to screen for genetic changes and has helped to identify differentially expressed genes (DEGs) and functional pathways involved in carcinogenesis and progression of RCC. However, the false positive rate in independent microarray analysis makes it difficult to achieve reliable results. In our study, 4 mRNA microarray datasets from Gene Expression Omnibus (GEO) were downloaded and analyzed to obtain DEGs from renal cancerous and non-cancerous tissues. Subsequently, further explorations were performed for the better understanding of the molecular mechanisms of renal cancer development and progression.

In this study, we analyzed the databases of GEO, TCGA, GEPIA, Oncomine, and found that six genes (SUCLG1, PCK2, GLDC, SLC12A1, ATP1A1, and
PDHA1), are related to the survival prognosis of patients with renal cancer. Furthermore, the functional verification of three genes (SUCLG1, PCK2 and GLDC) was performed in vitro experiments.

\section{Materials and methods Microarray data}

GEO is a public functional genomics data repository of high throughout gene expression data, microarrays, and chips [6]. Four gene expression datasets GSE781 [7], GSE6344 [8], GSE53000 [9] and GSE68417 [10] were downloaded from GEO GPL96, GPL96, GPL6244, GPL6244 platforms respectively. The GSE781 dataset contained 10 RCC tissue samples and 24 non-cancerous samples. The GSE6344 included 20 RCC samples and 20 non-cancerous samples. The GSE53000 contained 53 RCC samples and 6 non-cancerous samples. The GSE68417 included 29 ccRCC samples and 20 non-cancerous samples.

\section{Identification of DEGs}

The DEGs between ccRCC and non-cancerous samples were screened using GEO2R which is an interactive web tool that allows users to compare two or more datasets in a GEO series for identifying DEGs in experimental conditions. The adjusted P-values (adj. P) and Benjamini and Hochberg false discovery rate were applied to provide a balance between discovery of statistically significant genes and limitations of false-positives. Probe sets without corresponding gene symbols or genes with more than one probe set were removed or averaged, respectively. Adj. P-value $<0.01$ and logFC (fold change) $>1$ were considered statistically significant.

\section{KEGG and GO enrichment analyses of DEGs}

The Database for Annotation, Visualization and Integrated Discovery (DAVID; http://david.ncifcrf.gov) (version 6.8) [11] is an online biological information database that integrates biological data. DAVID is an analytic tool that provides a comprehensive set of functional annotation information of genes and proteins to users for extracting biological information. KEGG is a database resource for understanding high-level functions and biological systems from large-scale molecular datasets generated by high-throughput experimental technologies [12]. GO is a common bioinformatics tool that annotates and analyzes biological processes of the genes [13]. In order to explain the function of DEGs, biological analyses were performed using DAVID online database and $\mathrm{P}<0.05$ was considered statistically significant. 


\section{PPI network construction and module analysis}

The PPI network was predicted and structured using Search Tool for the Retrieval of Interacting Genes (STRING: http://string-db.org) (version 11.0) [14] through online database. Analyzing the functional interactions among proteins may provide further understanding of the mechanisms of origin and development of diseases. In our study, PPI network of DEGs was constructed using STRING database, and an interaction with a combined score $>0.4$ was considered statistically significant. Cytoscape (version 3.7.1) is an open source bioinformatics software platform for visualizing molecular interaction networks [15]. The plugin Molecular Complex Detection (MCODE) (version 1.5.1) of Cytoscape is an APP for clustering a given network based on topology to find densely connected regions [16]. The PPI networks were structured using Cytoscape software and the most significant module in the PPI networks of DEGs was identified using MCODE app. The criteria for selection included: MCODE scores $>5$, node score cut-off $=0.2$, degree cut-off $=2$, $\max$ depth $=100$ and $k$-score $=2$. Subsequently, the KEGG and GO analyses for these genes in the module were performed using DAVID.

\section{Hub genes selection and analysis}

The hub genes were selected with betweenness degrees $\geq 100$. The co-expression genes network was analyzed using cBioPortal online platform (http://www. cbioportal.org) [17, 18]. The biological process analysis of hub genes was performed and visualized employing Biological Networks Gene Oncology tool (BiNGO) (version 3.0.3) plugin of Cytoscape [19]. Hierarchical clustering of hub genes was analyzed using UCSC Cancer Genomics Browser (http://genome-cancer.ucsc.edu) [20]. The overall survival of hub genes was performed employing Kaplan-Meier curve in GEPIA (Gene Expression Profiling Interactive Analysis) [21]. The expression profiles of 6 hub gene (SUCLG1, GLDC, SLC12A1, PCK2, ATP1A1, PDHA1) were analyzed and displayed using UALCAN (http://ualcan.path.uab.edu/), and Oncomine (https:// www.oncomine.org/) online database.

\section{Reagents}

RPMI-1640 medium was purchased from Gibco Thermo Fisher Scientific, Inc. Fetal bovine serum (FBS) was purchased from Biological Industries. SUCLG1 (catalog no. 8072), PCK2 (catalog no. 6924), GLDC (catalog no. 12794) were primary antibodies bought from Cell Signalling Technology, Inc. The GAPDH antibody (catalog no. ab9485), secondary goat anti-rabbit antibody (catalog no. ab9485) were purchased from Santa Cruz Biotechnology, Inc.

\section{Cell culture and transfection}

Human renal carcinoma cell lines OSRC-2 and A498, obtained from the Cell Bank of Chinese Academy of Sciences (Shanghai, China), were cultured in RPMI-1640 medium supplemented with $10 \% \mathrm{FBS}$, and incubated at $37{ }^{\circ} \mathrm{C}$ with $5 \% \mathrm{CO}_{2}$. Cells in the logarithmic growth phase were used for subsequent experiments. OS-RC-2 and A498 cells were cultured in 6-well plates or $60 \mathrm{~mm}^{2}$ medium dishes and transfected with over expressed plasmids and negative control (NC) sequences that were purchased from Shanghai GenePharma Co., Ltd. (Shanghai, China). Transfection was conducted using Lipofectamine $^{\circledR} 3000$ (Thermo Fisher Scientific, Inc.). The cells were harvested at $48 \mathrm{~h}$ after transfection for reverse transcription-quantitative polymerase chain reaction (RT-qPCR) analysis.

\section{Reverse transcription-quantitative (RT-q) PCR}

Cell culture dishes were placed on ice, the culture medium was removed and cells were washed thrice with PBS. Total RNA was extracted using a Trizol ${ }^{\circledR}$ kit (Fastgene, Inc.; Catalog no. 220010). The extracted RNA was reverse transcribed into cDNA using a PrimeScript ${ }^{\circledR}$ RT Reagent kit with DNA Eraser (Takara Bio Inc.), as per the manufacturer's instructions. The sequences of the primers used were showed in Additional file 1: Table S1.

\section{Western blotting}

Protein samples were lysed at $4{ }^{\circ} \mathrm{C}$ using RIPA lysis buffer for $10 \mathrm{~min}$. The samples were then centrifuged at $12,000 \times g$ for $20 \mathrm{~min}$ at $4{ }^{\circ} \mathrm{C}$. The supernatants were obtained, and the protein concentration was quantified using the Coomassie Brilliant Blue method. The samples were mixed with $3 \times$ sample buffer solution and boiled for $5 \mathrm{~min}$. Protein samples were loaded on a 10\% SDS-gel and resolved using SDS-PAGE for $2 \mathrm{~h}$. The resolved proteins were then transferred to a nitrocellulose membrane, which were blocked with $5 \%$ skimmed milk for $2 \mathrm{~h}$ at room temperature and then membrane was cut according to the molecular weight of the protein of interest that was based on a pre-stained protein ladder. Subsequently, the membranes were incubated overnight at $4{ }^{\circ} \mathrm{C}$ with the primary antibody. The following day, the membranes were washed four times with TBST buffer and incubated with the appropriate secondary antibody $(1: 10,000)$ for $2 \mathrm{~h}$ at room temperature. These membranes were again washed four times with TBST and signals were visualized using enhanced chemiluminescent reagent. Densitometry analysis was performed using Image J. 


\section{Cell viability assays}

To perform cell viability assays, cells were counted and plated in the well of 96-well plate (1000 cells per well) $24 \mathrm{~h}$ after transfection. At the cell culture duration of 0 , 24, 48, 72, and $96 \mathrm{~h}(\mathrm{~s})$, the cell viability was measured using Cell Counting Kit-8 (CCK8) Assay Kit (Dojindo, China) according to the manufacturer's protocol.

\section{Cell proliferation evaluation}

The cell proliferation was detected using the incorporation of 5-Ethynyl-2'-deoxyuridine (EdU) with the EdU Cell Proliferation Assay Kit (Ribobio, Guangzhou, China). The cells were further incubated with $50 \mu \mathrm{M}$ EdU for $2 \mathrm{~h}$ before fixation, permeabilization and EdU staining, which were also performed according to the manufacturer's protocol. The cell nuclei were stained with Hoechst at a concentration of $1 \mu \mathrm{g} / \mathrm{mL}$ for $30 \mathrm{~min}$. The proportion of cells that incorporated EdU was determined using the fluorescence microscopy.

\section{Transwell migration and invasion assays}

Cells were trypsinized and the samples were centrifuged at $900 \times \mathrm{g}$ for $3 \mathrm{~min}$ at room temperature. After discarding the supernatant, the samples were resuspended in RPMI-1640 medium, centrifuged at $900 \times \mathrm{g}$ for $3 \mathrm{~min}$ at room temperature and the cells were washed with PBS. The cells were resuspended in $500 \mu \mathrm{l}$ RPMI-1640 medium and the density of cells was determined by hemocytometer. For the invasion assays, Transwell membranes were coated with Matrigel. A total of $2 \times 10^{4}$ cells were placed in the upper chamber of an 8 - $\mu \mathrm{m}$ pores microporous Transwell insert and in the lower chamber, $500 \mu \mathrm{l}$ RPMI-1640 supplemented with $10 \%$ FBS was added and then the cells were incubated. Migration and invasion was determined by counting the number of cells that had successfully migrated through the membrane (migration) or invaded through the Matrigel matrix (invasion). After $24 \mathrm{~h}$, the chamber was removed, cells which had not migrated or invaded were removed using a cotton swab, and the insert was dried at room temperature. Cells were subsequently fixed with $4 \%$ paraformaldehyde for $15 \mathrm{~min}$ at room temperature and dyed for 5 min using the crystal violet. After the filter membrane had dried, the sample was photographed.

\section{Wound healing assay}

The cells were first selected, digested and counted, then inoculated into 6-well plates and incubated overnight. The next day, SUCLG1, PCK2, GLDC and NC over expression plasmid were used for transfection. After $48 \mathrm{~h}$ of transfection and the confluence reaching to almost $100 \%$, a monolayer of the cells was scratched with a $200 \mu \mathrm{l}$ pipette tip and photographed using an inverted microscope at $\times 200$. The 6 -well plate was placed in the incubator and was again photographed after $24 \mathrm{~h}$. The scratched areas in the two photos were compared.

\section{Flow cytometry}

The effect of SUCLG1, PCK2, GLDC and NC over expression plasmid on cell cycle was detected. The cells to be treated were digested with trypsin, centrifuged at $900 \times g$ for $3 \mathrm{~min}$ at room temperature, then washed in PBS and suspended in $500 \mu \mathrm{l}$ buffer solution and fixed with $70 \%$ alcohol for $2 \mathrm{~h}$. Subsequently, $50 \mu \mathrm{l}$ RNase A was added to the $450-\mu \mathrm{l}$ Propidium Iodide. After fully mixing and incubating at room temperature for $5 \mathrm{~min}$, the cells were washed with $500 \mu$ buffer solution and resuspended. Proceeding further, $500 \mu \mathrm{l}$ mixed propidium iodide was added for $30 \mathrm{~min}$ at $37^{\circ} \mathrm{C}$. The samples were analysed using flow cytometer (BD FACSCalibur).

\section{Statistical analysis}

All data were analyzed using GraphPad Prism 7.0 statistical software (GraphPad Software, Inc., La Jolla, CA, USA) and SPSS 23.0 (IBM Corp., Armonk, NY, USA). The two-tailed paired Student's t-test was conducted for the analysis of the two groups. One-way analysis of variance (ANOVA) test and Bonferroni post hoc test were used for evaluating the differences among the multiple groups and $P<0.05$ was considered to indicate a statistically significant difference.

\section{Results \\ Identification of DEGs in RCC}

After standardization of the microarray results, DEGs (1657 in GSE781, 1347 in GSE6344, 1161 in GSE53000 and 1807 in GSE68417) were identified between renal cancerous and non-cancerous tissues. The overlap among the 4 datasets included 215 genes as shown in the Venn diagram (Fig. 1a).

(See figure on next page.)

Fig. 1 Identification of consistent DEGs in RCC. a Venn plot for consistent DEGs among the mRNA expression profiling sets GSE781, GSE68417, GSE6344, GSE53000. b The PPI network of DEGs was constructed using Cytoscape. c The most significant module was obtained from PPI network. $\mathbf{d}$ Hub genes and their co-expression genes were analyzed using cBioPortal. e The biological process analysis of hub genes was constructed. $\mathbf{f}$ Hierarchical clustering of hub genes was constructed using UCSC 


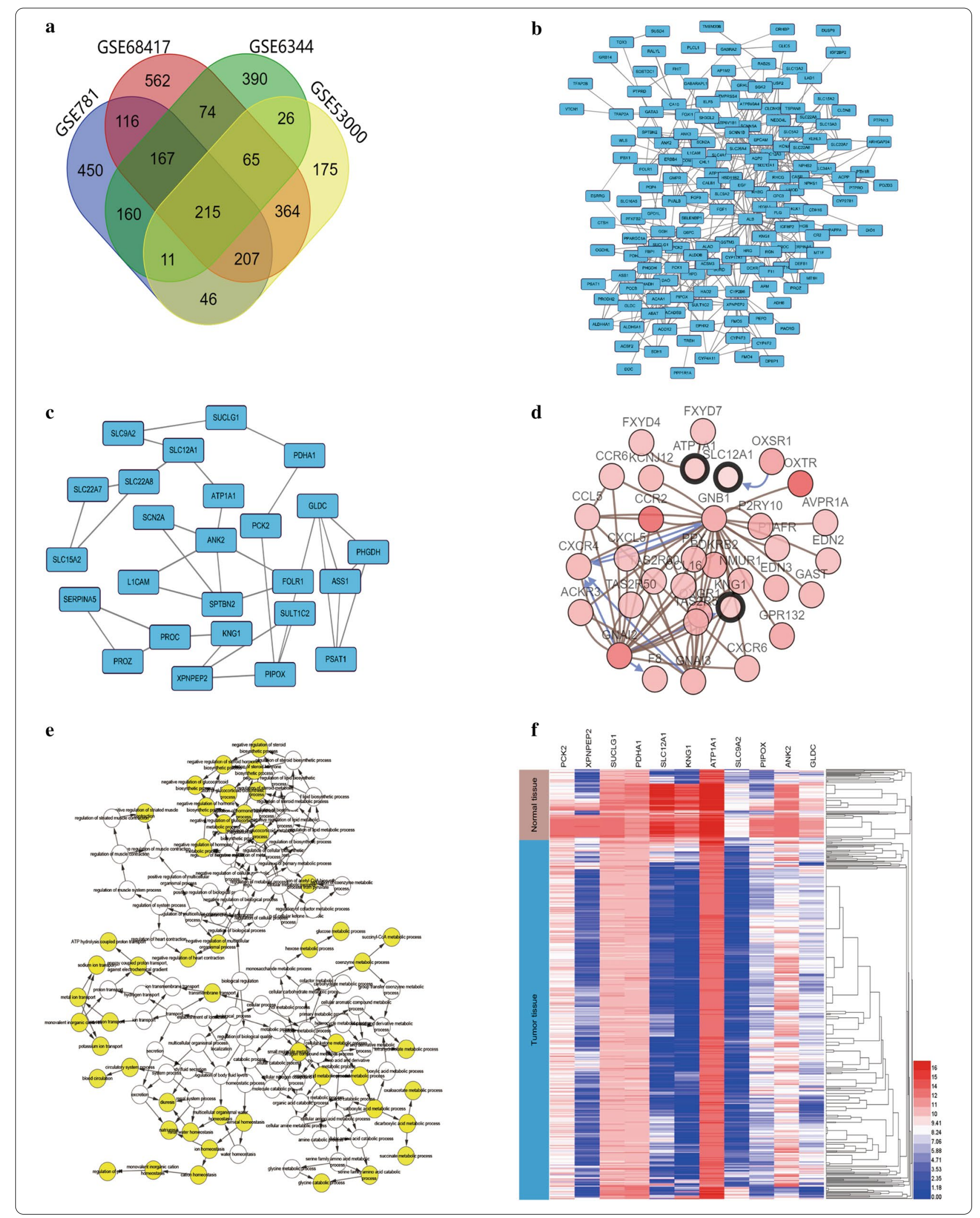




\section{KEGG and GO enrichment analyses of DEGs}

To analyze the biological classification of DEGs, function and pathway enrichment analyses were performed using DAVID. GO analysis results showed that changes in biological processes (BP) of DEGs were significantly enriched in carboxylic acid, organic acid and oxoacid metabolic processes. Changes in cell component (CC) of DEGs were mainly enriched in extracellular exosome, vesicle and organelle. Changes in molecular function (MF) were mainly enriched in cofactor binding, coenzyme binding and secondary active transmembrane transporter activity. KEGG pathway analysis revealed that DEGs were mainly enriched in metabolic pathways, biosynthesis of antibiotics and Carbon metabolism (Table 1).

\section{PPI network construction and module analysis}

The PPI network of DEGs was constructed (Fig. 1b) and the most significant module was identified using Cytoscape (Fig. 1c). The functional analysis of genes contained in this module was done using DAVID. GO analysis results showed that the genes in this module were mainly enriched in potassium ion transport, cellular chemical homeostasis, coenzyme metabolic process in BP; in mitochondrial matrix, apical plasma membrane, extracellular exosome in CC; in active transmembrane transporter activity in MF; in citrate cycle, biosynthesis of antibiotics and carbon metabolism in KEGG (Table 2).

\section{Hub gene selection and analysis}

A total of 11 genes were identified as hub genes with betweenness degrees $\geq 100$. The hub gene symbol, abbreviations and functions are shown in (Table 3). A network of the 11 hub genes and their co-expression genes was showed using cBioPortal online platform (Fig. 1d). The biological process analysis of the hub genes is shown in Fig. 1e. Hierarchical clustering showed that hub genes could basically differentiate the kidney cancer samples from the noncancerous samples (Fig. 1f). Subsequently, the overall survival analysis of 11 hub genes was performed using Kaplan-Meier curve in the GEPIA dataset. Kidney cancer patient with SUCLG1, GLDC, SLC12A1, PCK2, ATP1A1 and PDHA1 alteration showed highest mortality (Fig. 2a). The expression profile of the 6 genes in human tissue was displayed using UALCAN (Fig. 2b) and Oncomine (Additional file 2: Fig).

\section{Expression level of key genes in human RCC cell lines and tissues}

qRT-PCR analysis revealed that 6 genes (SUCLG1, PCK2, GLDC, SLC12A1, ATP1A1 and PDHA1) relative expression was significantly decreased in $6 \mathrm{RCC}$ cell lines compared to 293t cell line (Fig. 3a-f). Their expressions were also detected in primary tumor tissue and normal tissues using RT-PCR and Western blots. As expected, the mRNA expression and protein levels of the genes were down regulated in RCC samples compared to those in paracancerous normal tissues (Fig. $3 g-i)$.

\section{Over expression of the key genes inhibits the proliferation of RCC}

3 genes (SUCLG1, PCK2, GLDC) have not yet been researched to show the association with $\mathrm{RCC}$, so they were selected as the main study molecules. In order to evaluate the potential role of the 3 genes in RCC cell proliferation, the cell lines that were linearly over expressed SUCLG1, PCK2, GLDC were established. Their protein expression levels (transfected and control cells) were determined by q-PCR and Western blotting, which showed an increase in expression of both OSRC-2 and A498 cells compared to the empty vector-transfected cells (Fig. 4). Cell viability was assessed by CCK- 8 and Edu assay, and it was found that the number of OSRC-2 and A498 cells in which 3 genes were over expressed was decreased significantly. This illustrated that the 3 genes over expression reduced cellular growth and proliferation compared to the control cells (Fig. 5).

\section{SUCLG1, PCK2, GLDC inhibits the migration and invasion abilities of RCC cells}

To determine the effect of SUCLG1, PCK2, GLDC on the migration and invasiveness of RCC cells, transwell migration, matrigel invasion, and wound healing assays were performed. The number of migrated OSRC-2 cells in the experiment group was significantly decreased compared to the control group; the same result was observed in A498 cells of the experimental group (Fig. 6a, b). Additionally, 3 genes remarkably inhibited cell invasion abilities of OSRC-2 cells and A498 cells (Fig. 6c, d). Wound healing experiments revealed that the over expression SUCLG1, PCK2, GLDC significantly decreased the migration ability of OSRC-2 and A498 cells(Fig. 6e, h).

\section{SUCLG1, PCK2, GLDC induces G1/S/G2 phase arrest of RCC cells}

To determine, whether or not the cell proliferation of RCC cells was associated with cell cycle arrest, we investigated the cell cycle of OSRC-2 and A498 cells. Flow cytometry data showed that the cycle progression of the two cell lines was obviously inhibited in G1/S/G2 phase. For SUCLG1and PCK2, the cell cycle was inhibited in $S$ phase; For GLDC, G2/M phase was arrested (Fig. 6i, j). 
Table 1 GO and KEGG pathway enrichment analysis of DEGs in KIRC samples

\begin{tabular}{|c|c|c|c|}
\hline Term/pathway ID & Description & Count in gene set & P-value \\
\hline \multicolumn{4}{|l|}{$\mathrm{BP}$} \\
\hline GO:0019752 & Carboxylic acid metabolic process & 45 & $1.07 \mathrm{E}-16$ \\
\hline GO:0006082 & Organic acid metabolic process & 47 & $1.23 \mathrm{E}-16$ \\
\hline GO:0043436 & Oxoacid metabolic process & 45 & 1.33E-16 \\
\hline GO:0044282 & Small molecule catabolic process & 25 & $6.84 \mathrm{E}-12$ \\
\hline GO:0001822 & Kidney development & 22 & $1.91 \mathrm{E}-11$ \\
\hline GO:0072001 & Renal system development & 22 & $5.72 \mathrm{E}-11$ \\
\hline GO:0055114 & Oxidation-reduction process & 40 & $8.91 \mathrm{E}-11$ \\
\hline GO:0016054 & Organic acid catabolic process & 19 & $3.42 \mathrm{E}-10$ \\
\hline GO:0001655 & Urogenital system development & 22 & $5.53 \mathrm{E}-10$ \\
\hline GO:0006811 & Ion transport & 48 & $8.49 \mathrm{E}-10$ \\
\hline \multicolumn{4}{|l|}{$\mathrm{CC}$} \\
\hline GO:0070062 & Extracellular exosome & 101 & $9.00 \mathrm{E}-25$ \\
\hline GO:1903561 & Extracellular vesicle & 101 & 1.34E-24 \\
\hline GO:0043230 & Extracellular organelle & 101 & $1.38 \mathrm{E}-24$ \\
\hline GO:0031988 & Membrane-bounded vesicle & 107 & $7.12 \mathrm{E}-20$ \\
\hline GO:0044421 & Extracellular region part & 108 & $5.23 \mathrm{E}-18$ \\
\hline GO:0005576 & Extracellular region & 113 & $1.48 \mathrm{E}-14$ \\
\hline GO:0045177 & Apical part of cell & 26 & $1.04 \mathrm{E}-11$ \\
\hline GO:0016323 & Basolateral plasma membrane & 20 & $2.35 E-11$ \\
\hline GO:0016324 & Apical plasma membrane & 23 & 4.15E-11 \\
\hline GO:0098590 & Plasma membrane region & 39 & $3.45 E-10$ \\
\hline \multicolumn{4}{|l|}{ MF } \\
\hline GO:0048037 & Cofactor binding & 20 & 2.23E-09 \\
\hline GO:0050662 & Coenzyme binding & 14 & 7.50E-07 \\
\hline GO:0015291 & Secondary active transmembrane transporter activity & 15 & $1.92 \mathrm{E}-06$ \\
\hline GO:0008509 & Anion transmembrane transporter activity & 14 & $2.26 \mathrm{E}-06$ \\
\hline GO:0022804 & Active transmembrane transporter activity & 18 & $5.05 \mathrm{E}-06$ \\
\hline GO:0016614 & Oxidoreductase activity, acting on $\mathrm{CH}-\mathrm{OH}$ group of donors & 11 & $1.05 E-05$ \\
\hline GO:1901681 & Sulfur compound binding & 13 & 4.69E-05 \\
\hline GO:0015103 & Inorganic anion transmembrane transporter activity & 10 & $5.01 \mathrm{E}-05$ \\
\hline GO:0016709 & $\begin{array}{l}\text { Oxidoreductase activity, with incorporation or reduction of molecular } \\
\text { oxygen }\end{array}$ & 6 & $2.11 \mathrm{E}-04$ \\
\hline GO:0042802 & Identical protein binding & 34 & $2.45 \mathrm{E}-04$ \\
\hline \multicolumn{4}{|l|}{ KEGG } \\
\hline hsa01100 & Metabolic pathways & 48 & 3.79E-09 \\
\hline hsa01130 & Biosynthesis of antibiotics & 18 & $6.50 \mathrm{E}-08$ \\
\hline hsa01200 & Carbon metabolism & 12 & $2.45 \mathrm{E}-06$ \\
\hline hsa04960 & Aldosterone-regulated sodium reabsorption & 6 & 4.38E-04 \\
\hline hsa00010 & Glycolysis/Gluconeogenesis & 7 & 8.33E-04 \\
\hline hsa00280 & Valine, leucine and isoleucine degradation & 6 & $1.05 \mathrm{E}-03$ \\
\hline hsa00020 & Citrate cycle (TCA cycle) & 5 & $1.45 \mathrm{E}-03$ \\
\hline hsa00260 & Glycine, serine and threonine metabolism & 5 & $3.88 \mathrm{E}-03$ \\
\hline hsa04610 & Complement and coagulation cascades & 6 & $5.74 \mathrm{E}-03$ \\
\hline hsa04966 & Collecting duct acid secretion & 4 & $9.94 \mathrm{E}-03$ \\
\hline
\end{tabular}

$\mathrm{BP}$, biological process; $\mathrm{CC}$, cellular component; $\mathrm{MF}$, molecular function 
Table 2 GO and KEGG pathway enrichment analysis of DEGs in the most significant module

\begin{tabular}{|c|c|c|c|}
\hline Term/Pathway ID & Description & Count in gene set & P-value \\
\hline \multicolumn{4}{|l|}{$\mathrm{BP}$} \\
\hline GO:0006813 & Potassium ion transport & 4 & $2.29 \mathrm{E}-04$ \\
\hline GO:0055082 & Cellular chemical homeostasis & 5 & $5.69 \mathrm{E}-04$ \\
\hline GO:0006732 & Coenzyme metabolic process & 4 & $7.29 E-04$ \\
\hline GO:0019752 & Carboxylic acid metabolic process & 5 & $9.93 \mathrm{E}-04$ \\
\hline GO:0043436 & Oxoacid metabolic process & 5 & $1.02 \mathrm{E}-03$ \\
\hline GO:0019725 & Cellular homeostasis & 5 & $1.02 \mathrm{E}-03$ \\
\hline GO:0051186 & Cofactor metabolic process & 4 & $1.30 E-03$ \\
\hline GO:0006082 & Organic acid metabolic process & 5 & $1.41 \mathrm{E}-03$ \\
\hline GO:0035383 & Thioester metabolic process & 3 & $1.44 \mathrm{E}-03$ \\
\hline GO:0006637 & Acyl-CoA metabolic process & 3 & $1.44 \mathrm{E}-03$ \\
\hline \multicolumn{4}{|l|}{ CC } \\
\hline GO:0005759 & Mitochondrial matrix & 4 & $1.83 \mathrm{E}-03$ \\
\hline GO:0016324 & Apical plasma membrane & 3 & $1.33 \mathrm{E}-02$ \\
\hline GO:0070062 & Extracellular exosome & 6 & $1.70 \mathrm{E}-02$ \\
\hline GO:1903561 & Extracellular vesicle & 6 & $1.74 \mathrm{E}-02$ \\
\hline GO:0043230 & Extracellular organelle & 6 & $1.74 \mathrm{E}-02$ \\
\hline GO:0044429 & Mitochondrial part & 4 & $1.94 \mathrm{E}-02$ \\
\hline GO:0045177 & Apical part of cell & 3 & $1.98 \mathrm{E}-02$ \\
\hline GO:0030315 & T-tubule & 2 & $2.63 E-02$ \\
\hline GO:0014704 & Intercalated disc & 2 & $3.06 \mathrm{E}-02$ \\
\hline GO:0044291 & Cell-cell contact zone & 2 & $4.08 \mathrm{E}-02$ \\
\hline \multicolumn{4}{|l|}{ MF } \\
\hline GO:0022804 & Active transmembrane transporter activity & 3 & $2.22 \mathrm{E}-02$ \\
\hline \multicolumn{4}{|l|}{ KEGG } \\
\hline hsa00020 & Citrate cycle (TCA cycle) & 3 & $5.07 E-04$ \\
\hline hsa01130 & Biosynthesis of antibiotics & 4 & $1.44 \mathrm{E}-03$ \\
\hline hsa01200 & Carbon metabolism & 3 & $7.02 \mathrm{E}-03$ \\
\hline hsa04964 & Proximal tubule bicarbonate reclamation & 2 & $2.65 E-02$ \\
\hline hsa01100 & Metabolic pathways & 5 & $3.76 \mathrm{E}-02$ \\
\hline hsa00260 & Glycine, serine and threonine metabolism & 2 & $4.45 E-02$ \\
\hline hsa00620 & Pyruvate metabolism & 2 & $4.56 \mathrm{E}-02$ \\
\hline
\end{tabular}

$\mathrm{BP}$, biological process; $\mathrm{CC}$, cellular component; $\mathrm{MF}$, molecular function

\section{Discussion}

In our present study, we investigated the roles of the SUCLG1, PCK2, GLDC in RCC. We found that the over expressions of these three genes significantly impaired the RCC process. Thus, targeting SUCLG1, PCK2, GLDC protein may be a useful strategy to inhibit tumor progression.

In the present study, four mRNA microarray datasets were analyzed to obtain DEGs between kidney cancer tissue and non-cancerous tissue. A total of 215 DEGs were identified in 4 datasets. GO and KEGG enrichment analysis indicated that these genes were mainly enriched in carboxylic acid, organic acid and oxoacid metabolic process, along with extracellular exosome, vesicle and organelle, including cofactor binding, coenzyme binding, secondary active transmembrane transporter activity, metabolic pathways, biosynthesis of antibiotics and carbon metabolism. Previous studies have reported that the dysregulation of carboxylic acid, organic acid and oxoacid play important role in the carcinogenesis or progression of cancers [22, 23]. Furthermore, it has been found that extracellular exosome, vesicle and organelle promote the tumor [24]. Moreover, studies have shown that cofactor binding, coenzyme binding, and secondary active transmembrane transporter activity often play a major role in the progression of cancer [25-27]. In conclusion, all these theories are consistent with our results. GO enrichment analysis revealed that changes 
Table 3 Functional roles of 11 hub genes with betweenness degrees $\geq 10$

\begin{tabular}{|c|c|c|c|}
\hline No. & Gene symbol & Full name & Function \\
\hline 1 & ANK2 & Ankyrin 2 & $\begin{array}{l}\text { Attaches integral membrane proteins to cytoskeletal elements.Also binds to } \\
\text { cytoskeletal proteins. Plays a role in endocytosis and intracellular protein transport }\end{array}$ \\
\hline 2 & SUCLG1 & Succinate-CoA Ligase Alpha Subunit & $\begin{array}{l}\text { Succinyl-CoA synthetase functions in the citric acid cycle, coupling the hydrolysis } \\
\text { of succinyl-CoA to the synthesis of either ATP or GTP }\end{array}$ \\
\hline 3 & GLDC & Glycine Decarboxylase & $\begin{array}{l}\text { The } P \text { protein }(G L D C) \text { binds the alpha-amino group of glycine through its pyridoxal } \\
\text { phosphate cofactor; } \mathrm{CO}_{2} \text { is released and the remaining methylamine moiety is } \\
\text { then transferred to the lipoamide cofactor of the } \mathrm{H} \text { protein }(\mathrm{GCSH})\end{array}$ \\
\hline 4 & SLC12A1 & Solute Carrier Family 12 Member 1 & $\begin{array}{l}\text { Mediates sodium and chloride reabsorption. Plays a vital role in the regulation of } \\
\text { ionic balance and cell volume }\end{array}$ \\
\hline 5 & PIPOX & Pipecolic Acid And Sarcosine Oxidase & Metabolizes sarcosine, L-pipecolic acid and L-proline \\
\hline 6 & KNG1 & Kininogen 1 & $\begin{array}{l}\text { Kininogens } 1 \text { is inhibitors of thiol proteases; plays an important role in blood coag- } \\
\text { ulation; inhibits the thrombin- and plasmin-induced aggregation of thrombocytes }\end{array}$ \\
\hline 7 & SLC9A2 & Solute Carrier Family 9 Member A2 & $\begin{array}{l}\text { Involved in pH regulation to eliminate acids generated by active metabolism or to } \\
\text { counter adverse environmental conditions }\end{array}$ \\
\hline 8 & PCK2 & Phosphoenolpyruvate Carboxykinase 2 & Catalyzes the conversion of oxaloacetate to phosphoenolpyruvate \\
\hline 9 & XPNPEP2 & X-Prolyl Aminopeptidase 2 & $\begin{array}{l}\text { Membrane-bound metalloprotease which catalyzes the removal of a penultimate } \\
\text { prolyl residue from the N-termini of peptides. May play a role in the metabolism of } \\
\text { the vasodilator bradykinin }\end{array}$ \\
\hline 10 & ATP1A1 & ATPase $\mathrm{Na}^{+} / \mathrm{K}^{+}$Transporting Subunit Alpha 1 & $\begin{array}{l}\text { This action creates the electrochemical gradient of sodium and potassium ions, } \\
\text { providing the energy for active transport of various nutrients }\end{array}$ \\
\hline 11 & PDHA1 & Pyruvate Dehydrogenase E1 Alpha 1 Subunit & $\begin{array}{l}\text { The pyruvate dehydrogenase complex catalyzes the overall conversion of pyruvate } \\
\text { to acetyl-CoA and } \mathrm{CO} 2 \text {, and thereby links the glycolytic pathway to the tricarbox- } \\
\text { ylic cycle. }\end{array}$ \\
\hline
\end{tabular}

in the most significant modules were mainly found in potassium ion transport, cellular chemical homeostasis, coenzyme metabolic process, mitochondrial matrix, apical plasma membrane, extracellular exosome and active transmembrane transporter activity, while changes in KEGG were mainly in citrate cycle, biosynthesis of antibiotics and carbon metabolism.

Using GEPIA for survival analysis of these 11 genes, showed that 6 genes (SUCLG1, PCK2, GLDC, SLC12A1, ATP1A1, PDHA1) had prognostic value in RCC patients, and may be involved in the carcinogenesis of the disease. Subsequently, We analyzed the expression of these 6 genes in 7 cell lines (293t, OSRC-2, A498, 786-O, Caki$1, \mathrm{ACHN}, 769-\mathrm{P})$ and found that their expressions were all down-regulated. Meanwhile, tissues of 8 patients with renal cancer were randomly selected, and the expression of these 6 genes was detected in these tissues. The results showed that their expressions were also down-regulated. Furthermore, we tested the tissue samples of patients by western blot, suggesting that the protein expression was down-regulated (normal tissue adjacent to cancer vs tumor tissue). Many studies have shown that SLC12A1, ATP1A1, and PDHA1 are low-expressed in renal cancer and play an important role in the development of tumors. We have performed qPCR in cell lines and tissue of patients and the results are consistent with those of the predecessors. In order to clarify the molecular mechanism of these genes, we selected 3 molecules (SUCLG1,
PCK2, GLDC) that have not previously been studied in renal cancer, and conducted in vitro experiments on them.

SUCLG1 is a rate-limiting enzyme for the formation of high-energy phosphate bonds between ATP and GTP in the tricarboxylic acid cycle, and its abnormal expression affects the energy metabolism, leading to tumorigenesis. Here, we showed that SUCLG1 was significantly down regulated in both human kidney cancer tissues and cell lines. PCK2 is a rate-limiting enzyme of the metabolic pathway and is involved in the gluconeogenesis pathway, tumorigenesis and development [28]. PCK2 expression is important in maintaining the tumor cells in vitro under limited glucose conditions and metabolic enzymes are necessary for proliferation and tumor growth in vivo. PCK2 has a tumor suppressing effect in melanoma and liver cancer $[29,30]$, and has a pro-cancer effect in lung and breast cancer [31, 32].

In melanoma, PCK2 down-regulation accelerates the biosynthesis and transport of citric acid from mitochondria to the cytoplasm. Over expression of PCK2 slows the growth of tumor repopulating cell (TRC) in vitro and reduces tumorigenesis in vivo [29]. In lung cancer samples, PCK2 activity is 3 times higher compared to the normal tissues [31]. In prostate cancer, PCK2 highexpressing patients have more aggressive tumors with low survival rates [28]. However, the function of PCK2 has not been investigated in kidney cancer. This experiment 

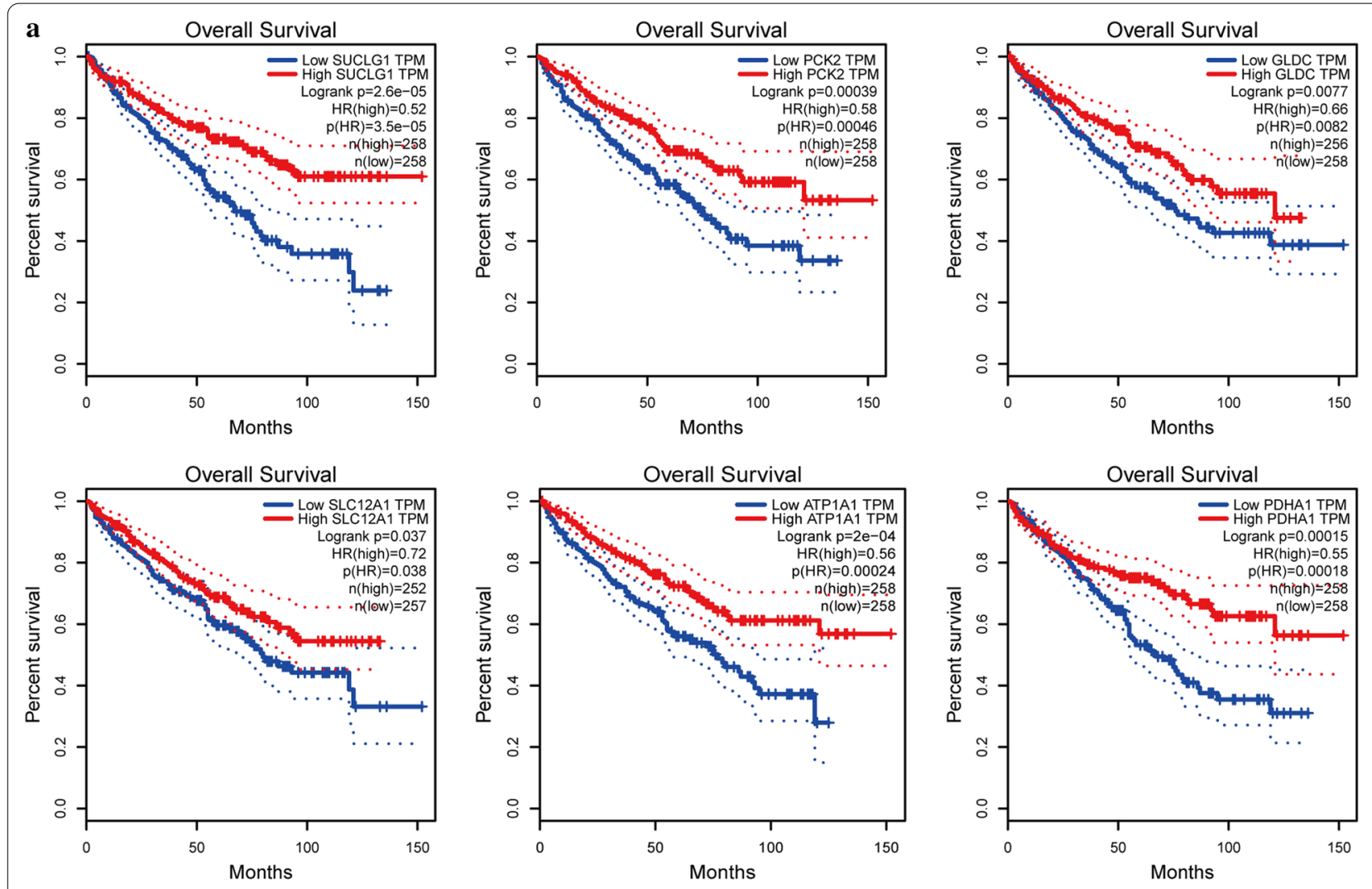

b Expression of SUCLG1 in RCC based on samlpe types

Expression of PCK2 in RCC based on samlpe types
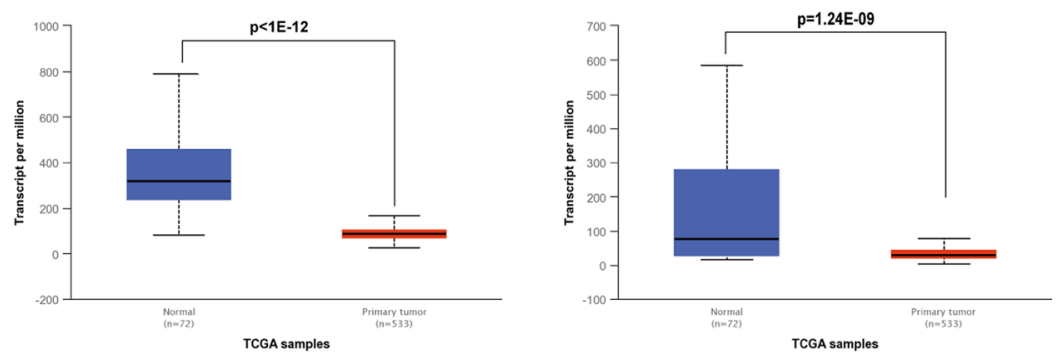

Expression of GLDC in RCC based on samlpe types

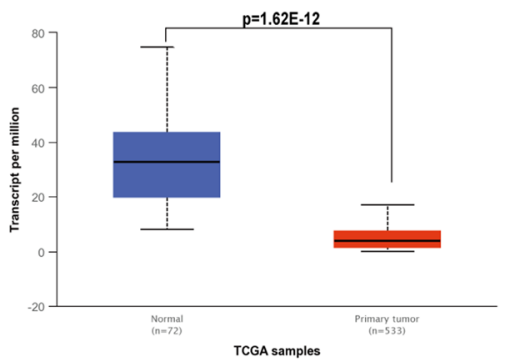

Expression of SLC12A1 in RCC based on samlpe types

Expression of ATP1A1 in RCC based on samlpe types
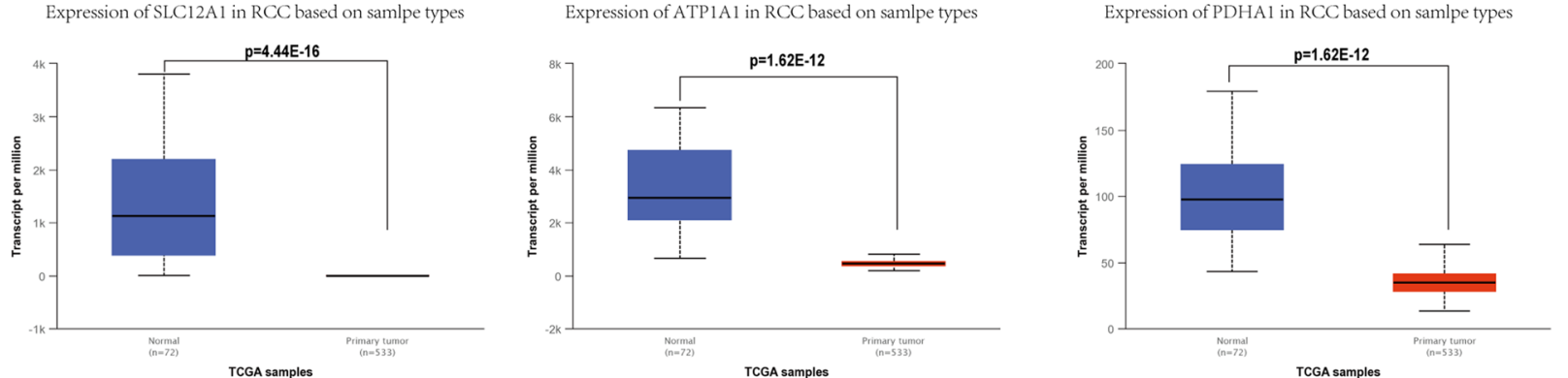

Fig. 2 Survival and different analysis of the hub genes. a The survival curve of SUCLG1, PCK2, GLDC, SLC12A1, ATP1A1, PDHA1. b Analysis of differential expression in normal controls and patients with cancer based on SUCLG1, PCK2, GLDC, SLC12A1, ATP1A1, PDHA1 using the sample of The Cancer Genome Atlas database 


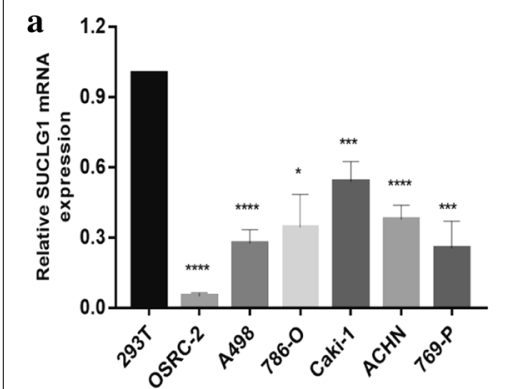

d

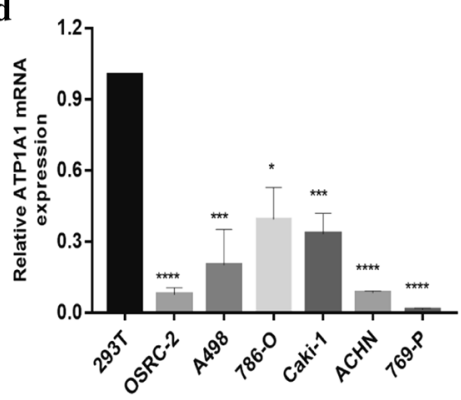

g

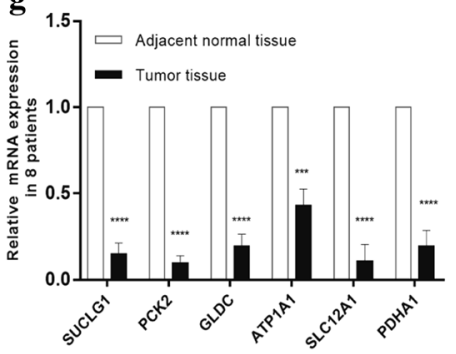

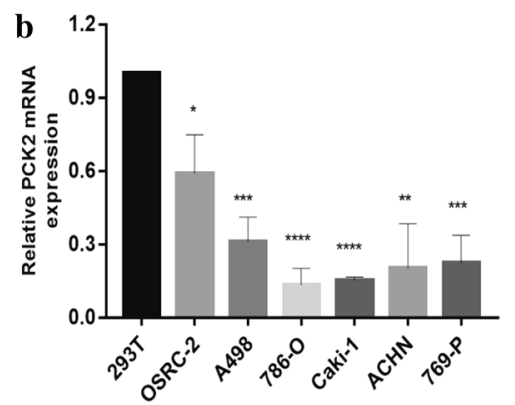

e

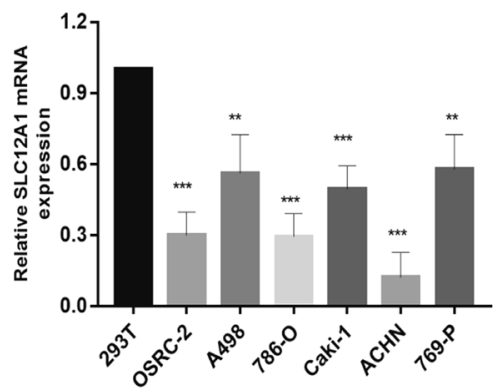

h

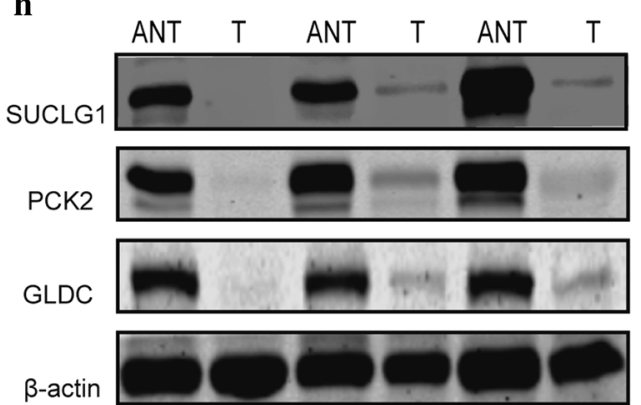

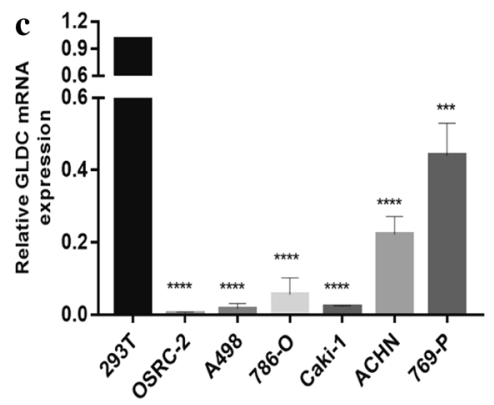

f
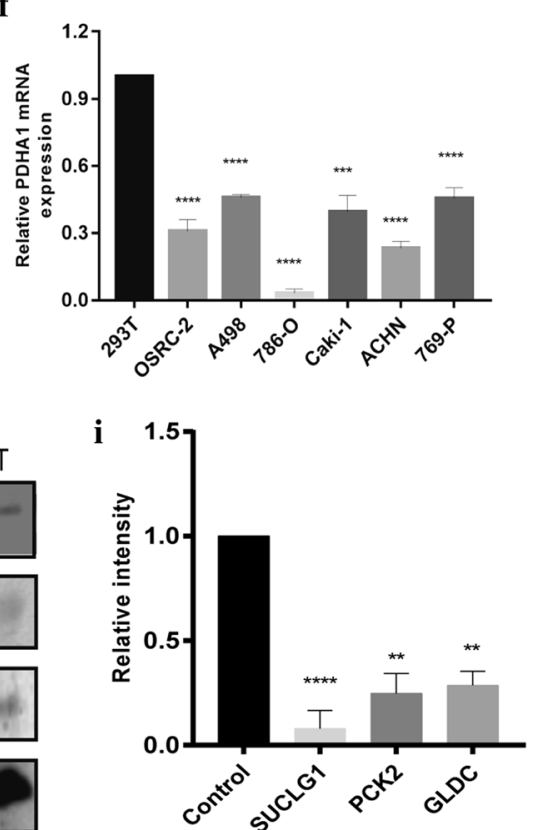

Fig. 3 RT-qPCR and western blotting of the expression level of key genes in RCC cell lines. a-f RT-qPCR detection of mRNA expression of SUCLG1, PCK2, GLDC, SLC12A1, ATP1A1, PDHA1 in seven RCC cell lines. $\mathbf{g}$ Key genes mRNA expression level in eight paired kidney tumor tissues. $\mathbf{h}$ SUCLG1, PCK2, GLDC protein expression level in eight paired kidney tumor tissues ( $T$ ) and their adjacent normal tissues (ANT). $\mathbf{i}$ The values of the band intensity represent the densitometric estimation of each band normalised by $\beta$-actin in $(H) .\left({ }^{*} p<0.05,{ }^{* *} p<0.01,{ }^{* * *} p<0.001\right.$, and $\left.{ }^{* * * *} p<0.001\right)$

analyzed the expression of PCK2 in kidney cancer tissues and cell lines, and found that the expression of PCK2 is down-regulated. GLDC is mainly involved in regulating glycine metabolism and is one of the core metabolic enzymes for protein and amino acid metabolism. A research found that GLDC is over expressed in non-small cell lung cancer stem cells and accelerates the tumorigenesis by enhancing glycolysis and pyrimidine metabolism in non-cell lung cancer stem cells [33]. In addition,
Jäger et al. found that GLDC was highly expressed in melanoma [34] whereas Min et al. found that GLDC was low expressed in gastric cancer [35]. Our study analyzed GLDC in renal cancer tissue and cells. The expression of GLDC was found to be down-regulated. In order to clarify the mechanisms of SUCLG1, PCK2, and GLDC in renal cancer, this study further focused on their proliferation, migration, invasion, and cell cycle of renal cancer cells through cell biology experiments.

Fig. 4 RT-qPCR and western blotting validation of the expression level of SUCLG1, PCK2, GLDC in OSRC-2 and A498 cell lines. a-c Forty-eight hours after plasmid or vector transfection, aPCR detected the expression level of 3 genes in both OSRC-2 and A498 cell lines. b-f Protein expression was evaluated by Western blot. $\mathbf{j}$-I The values of the band intensity represent the densitometric estimation of each band normalised by $\beta$-actin in ( $\mathbf{b}-\mathbf{f}$, respectively). $\left({ }^{*} p<0.05\right.$ and $\left.{ }^{* *} p<0.01\right)$ 


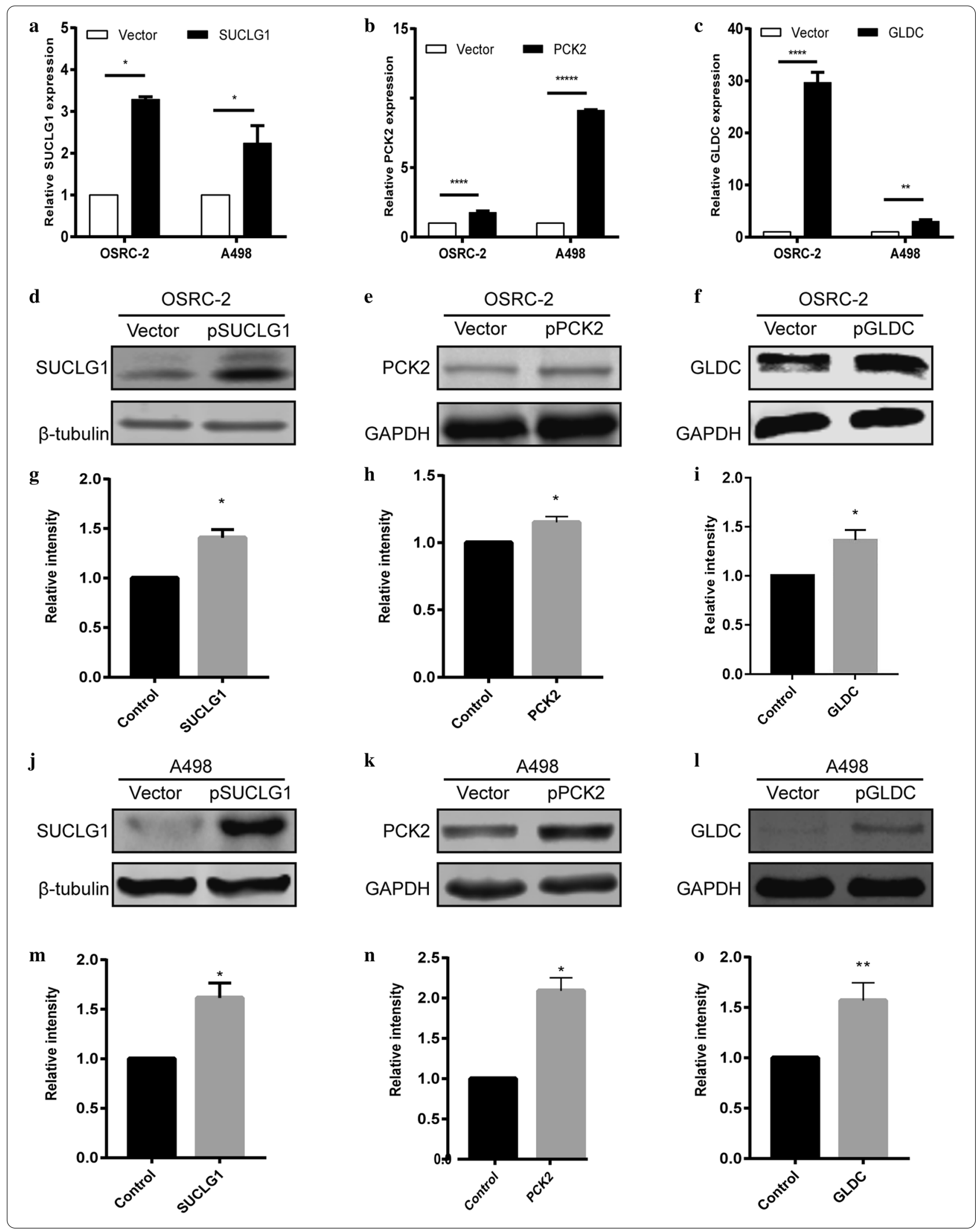



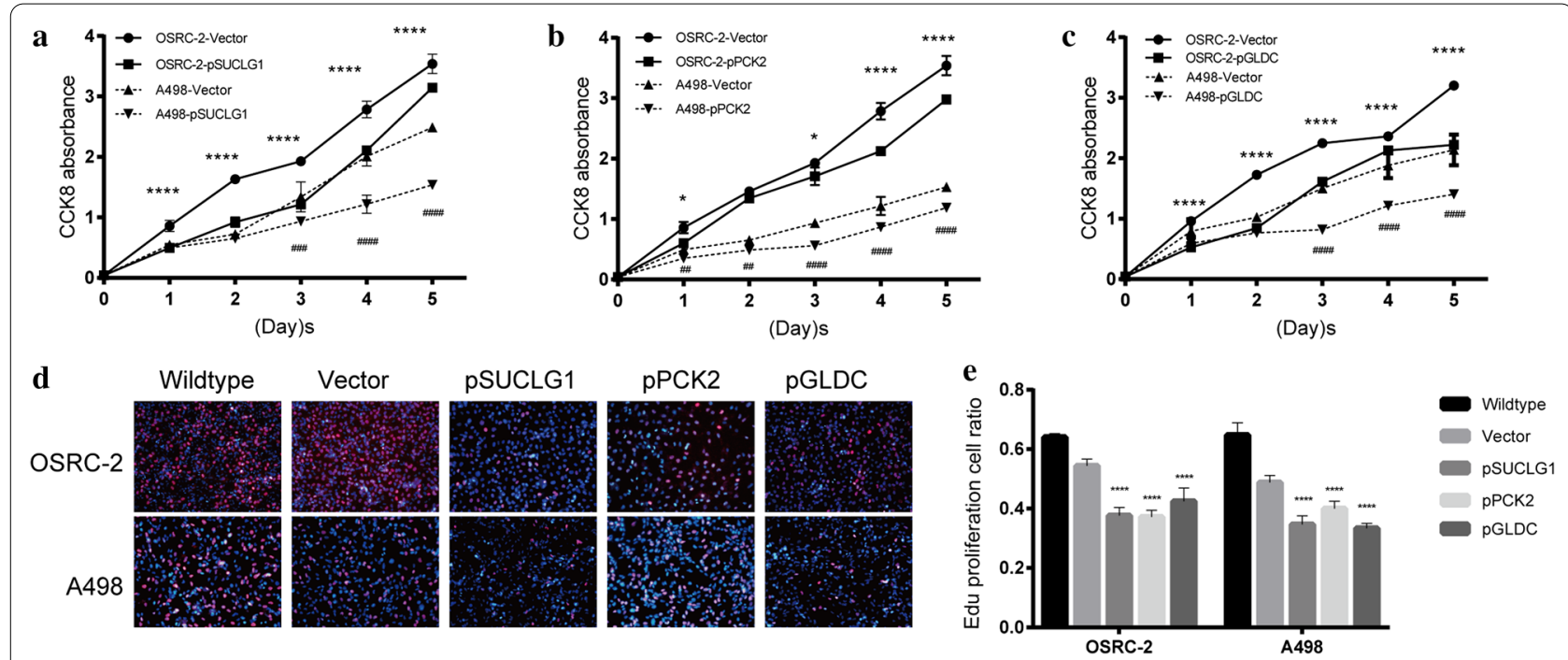

Fig. 5 CCK-8 and Edu cell proliferation assay were performed after SUCLG1, PCK2, GLDC over-expression in OSRC-2 and A498. a-c CCK-8 cell proliferation assay. $\mathbf{d}$ Edu cell proliferation assay. e Quantification to Edu cell proliferation assay. ${ }^{*} p<0.05,{ }^{* *} p<0.01,{ }^{* * *} p<0.001$, and $\left.{ }^{* * *} p<0.001\right)$

Although the results of our current study indicated possible crucial roles of SUCLG1, PCK2, and GLDC in RCC, further studies, for example, the conduct of the rescue experiments, and in vivo studies will be helpful for the further validation of our present findings, and the better understanding of the mechanisms.
In conclusion, the experimental results showed that over expression of SUCLG1, PCK2, and GLDC can inhibit the progression of renal cancer cells. Therefore, UCLG1, PCK2, GLDC, have the potential to be a novel and valuable oncotarget protein for human kidney cancer.

(See figure on next page.)

Fig. 6 Over-expression of SUCLG1, PCK2, GLDC inhibits renal carcinoma cell migration and invasion in vitro. a Transwell cell migration assay was performed after the overexpression in OSRC-2 and A498 cells. b Quantitative analysis to (a). c Matrigel cell invasion assay was performed after the overexpression in OSRC-2 and A498 cells. d Quantitative analysis to (c). e-g Overexpression SUCLG1, PCK2, GLDC suppressed wound healing of OSRC-2 and A498 cell line. $\mathbf{f}-\mathbf{h}$ Quantitative description to (e) and (g). i Cell cycle of overexpression SUCLG1, PCK2, GLDC after transfection $48 \mathrm{~h}$ was analyzed by flow cytometry. Image shows a representative experiment out of three. Data was performed as mean \pm SD of three independent experiments. $\left({ }^{*} p<0.05,{ }^{* *} p<0.01,{ }^{* * *} p<0.001\right.$, and $\left.{ }^{* * *} p<0.001\right)$ 


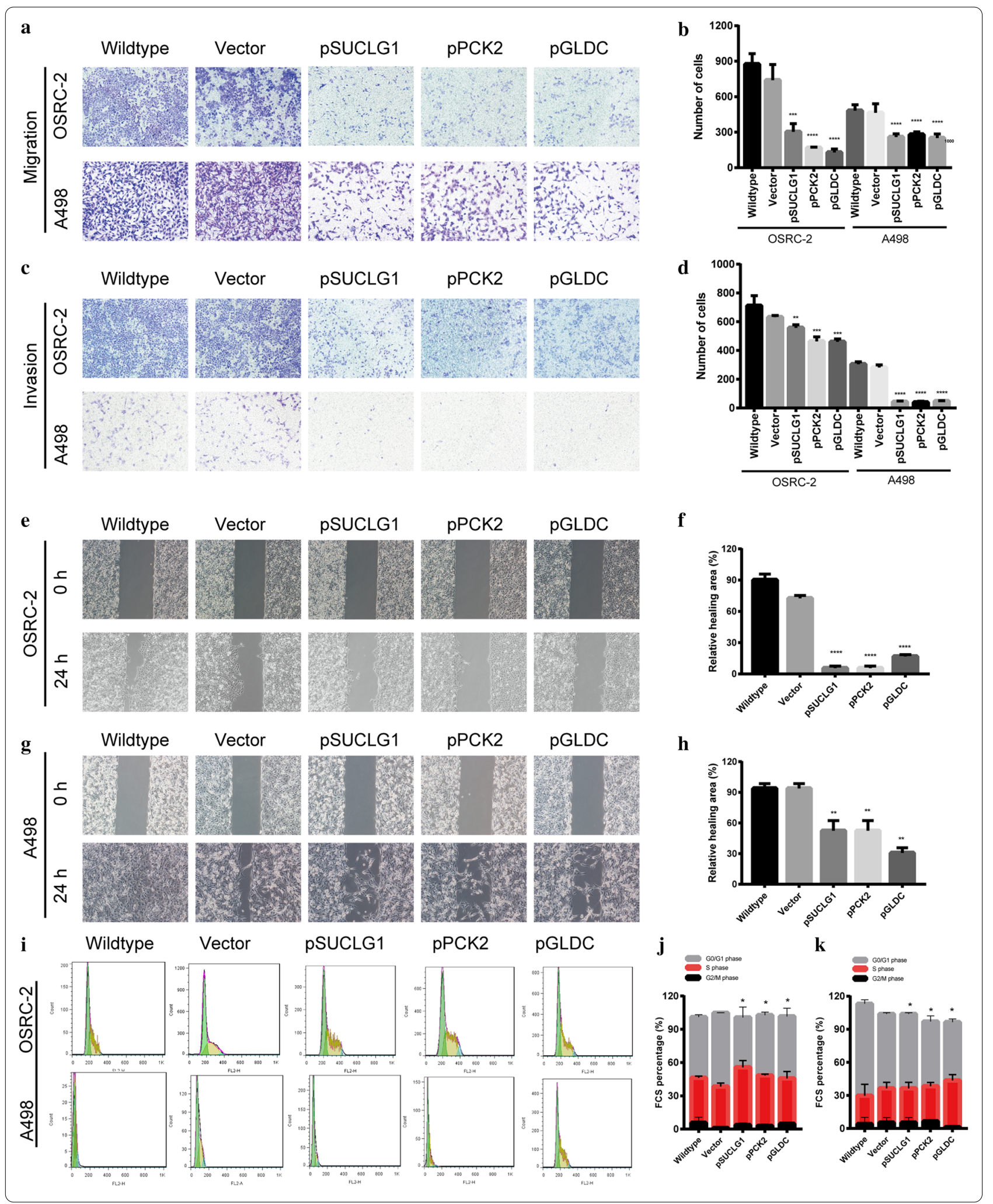




\section{Abbreviations}

RCC: Renal cell carcinoma RCC; GEO: Gene Expression Omnibus; DEGs: Differentially expressed genes; PPI: Protein-protein interaction network; TCGA: The Cancer Genome Atlas; SLC12A1: Solute carrier family 12 member 1; ATP1A1: Sodium/potassium-transporting ATPase subunit alpha-1; PDHA1: Pyruvate dehydrogenase E1 component subunit alpha; SUCLG1: Succinate CoA ligase subunit alpha; PCK2: Phosphoenolpyruvate carboxykinase; GLDC: Glycine dehydrogenase; DAVID: Database for Annotation Visualization and Integrated Discovery; STRING: Search Tool for the Retrieval of Interacting Genes; MCODE: Molecular Complex Detection; BiNGO: Biological Networks Gene Oncology tool; GEPIA: Gene Expression Profiling Interactive Analysis; FBS: Fetal bovine serum; EdU: 5-Ethynyl-2'-deoxyuridin; ANOVA: One-way analysis of varianc; BP: Biological processes; CC: Cell component; MF: Molecular function.

\section{Supplementary information}

Supplementary information accompanies this paper at https://doi.org/10. 1186/s12935-020-01405-6.

Additional file 1: Table S1. The sequences of the primers

Additional file 2: Figure S1. Expression of genes in the Oncomine

\section{Acknowledgements}

We thank the TCGA, UALCAN, GEPIA, STING, KEGG, GO and Oncomine program for kindly providing publicly available data for analysis.

\section{Authors' contributions}

YC conceived and designed the study, DG crafted the literature search, figures and tables and was responsible for the writing and critical reading of the manuscript. YW conducted bioinformatic analyses of gene expression profile datasets for the RCC patients. SY performed a majority of experiments in this study. $X D$, and $Y L$ contributed to the data analysis and the critical reading of manuscript. JY and DY provided human RCC tissue samples. AK supervised and contributed to the critical reading of manuscript. All authors read and approved the final manuscript.

\section{Funding}

This work was financed by grants from the National Natural Science Foundation of China (No. 81670643, 81870483 and 81803576), the Collaborative Innovation Project of Guangzhou Education Bureau (NO. 1201620011) the Guangzhou Science Technology and Innovation Commission (No. 201704020193), and the Science and Technology Planning Project of Guangdong Province (No.2017B030314108).

\section{Availability of data and materials}

The datasets used and/or analyzed during the current study are available from the corresponding author on reasonable request

\section{Ethics approval and consent to participate}

The study was approved by the ethics committee of The First Affiliated Hospital of Guangzhou Medical University.

\section{Consent for publication}

Not applicable yet.

\section{Competing interests}

The authors declare that they have no competing

\section{Author details}

${ }^{1}$ Department of Urology, Minimally Invasive Surgery Center, The First Affiliated Hospital of Guangzhou Medical University, Guangdong Key Laboratory of Urology, Kangda Road 1\#, Haizhu District, Guangzhou 510230, Guangdong, China. ${ }^{2}$ Department of Urology, Affiliated Cancer Hospital and Institute of Guangzhou Medical University, Guangzhou, China. ${ }^{3}$ Department of Family Medicine, Yunshan Medical Hospital, Shenzhen, China.
Received: 14 February 2020 Accepted: 7 July 2020

Published: 21 July 2020

\section{References}

1. Arakaki R, Yamasaki T, Kanno T, et al. CCL2 as a potential therapeutic target for clear cell renal cell carcinoma. Cancer Med. 2016;5:2920-33.

2. Vasudev NS, Selby PJ, Banks RE. Renal cancer biomarkers: the promise of personalized care. BMC Med. 2012;10:112.

3. Zhu X, Liang J, Shrubsole MJ, et al. Calcium intake and ion transporter genetic polymorphisms interact in human colorectal neoplasia risk in a 2-phase study. J Nutr. 2014;144:1734-41.

4. He Y, Zhang P, Zhang D, et al. Combined assessment of low PGRMC1/ positive ATP1A1 levels has enhanced prognostic value for renal cell carcinoma. Oncol Rep. 2018:40:1467-76.

5. Lin CS, Lee HT, Lee MH, et al. Role of mitochondrial DNA copy number alteration in human renal cell carcinoma. Int J Mol Sci. 2016;17(6):814-28.

6. Edgar R, Domrachev M, Lash AE. Gene expression omnibus: NCBI gene expression and hybridization array data repository. Nucleic Acids Res. 2002:30:207-10.

7. Lenburg ME, Liou LS, Gerry NP, Frampton GM, Cohen HT, Christman MF. Previously unidentified changes in renal cell carcinoma gene expression identified by parametric analysis of microarray data. BMC Cancer. 2003;3:31.

8. Gumz ML, Zou H, Kreinest PA, et al. Secreted frizzled-related protein 1 loss contributes to tumor phenotype of clear cell renal cell carcinoma. Clin Cancer Res. 2007;13:4740-9.

9. Gerlinger M, Horswell S, Larkin J, et al. Genomic architecture and evolution of clear cell renal cell carcinomas defined by multiregion sequencing. Nat Genet. 2014;46:225-33.

10. Thibodeau BJPD, Fulton MMD, Fortier LEMS, et al. Characterization of clear cell renal cell carcinoma by gene expression profiling. Urol Oncol Semin Original Investigations. 2015;34:161-8.

11. Huang DW, Sherman BT, Tan Q, et al. The DAVID gene functional classification tool: a novel biological module-centric algorithm to functionally analyze large gene lists. Genome Biol. 2007;8:R183.

12. Kanehisa M. The KEGG database. Novartis Found Symp. 2002; 247: 91-101, 101-103, 119-128, 244-252.

13. Ashburner M, Ball CA, Blake JA, et al. Gene ontology: tool for the unification of biology. The Gene Ontology Consortium. Nat Genet. 2000;25:25-9.

14. Szklarczyk D, Gable AL, Lyon D, et al. STRING v11: protein-protein association networks with increased coverage, supporting functional discovery in genome-wide experimental datasets. Nucleic Acids Res. 2019;47:D607-13.

15. Van Parys T, Melckenbeeck I, Houbraken M, et al. A cytoscape app for motif enumeration with ISMAGS. Bioinformatics. 2017;33:461-3.

16. Bader GD, Hogue CW. An automated method for finding molecular complexes in large protein interaction networks. BMC Bioinformatics. 2003:4:2.

17. Gao J, Aksoy BA, Dogrusoz U, et al. Integrative analysis of complex cancer genomics and clinical profiles using the cBioPortal. Sci Signal. 2013:6:11.

18. Cerami E, Gao J, Dogrusoz U, et al. The cBio cancer genomics portal: an open platform for exploring multidimensional cancer genomics data. Cancer Discov. 2012;2:401-4.

19. Maere S, Heymans K, Kuiper M. BiNGO: a Cytoscape plugin to assess overrepresentation of gene ontology categories in biological networks. Bioinformatics (Oxford, England). 2005:21:3448-9.

20. Haeussler M, Zweig AS, Tyner C, et al. The UCSC genome browser database: 2019 update. Nucleic Acids Res. 2019;2019(47):D853-8.

21. Tang Z, Li C, Kang B, Gao G, Li C, Zhang Z. GEPIA: a web server for cancer and normal gene expression profiling and interactive analyses. Nucleic Acids Res. 2017:45:W98-102. 
22. Cardaci S, Zheng L, MacKay G, et al. Pyruvate carboxylation enables growth of SDH-deficient cells by supporting aspartate biosynthesis. Nat Cell Biol. 2015;17:1317-26.

23. Liu Y, LiW, Duan Y. Effect of $\mathrm{H} 2 \mathrm{O} 2$ induced oxidative stress (OS) on volatile organic compounds (VOCs) and intracellular metabolism in MCF-7 breast cancer cells. J Breath Res. 2019;13:36005.

24. Grange C, Brossa A, Bussolati B. Extracellular vesicles and carried miRNAs in the progression of renal cell carcinoma. Int J Mol Sci. 2019;20:1832.

25. Grabmaier K, Weijert MC, Verhaegh GW, Schalken JA, Oosterwijk E. Strict regulation of CAIX(G250/MN) by HIF-1alpha in clear cell renal cell carcinoma. Oncogene. 2004;23:5624-31.

26. Woodard J, Sassano A, Hay N, Platanias LC. Statin-dependent suppression of the Akt/mammalian target of rapamycin signaling cascade and programmed cell death 4 up-regulation in renal cell carcinoma. Clin Cancer Res. 2008;14:4640-9.

27. Wilson MR, Hou Z, Wilson LJ, Ye J, Matherly LH. Functional and mechanistic roles of the human proton-coupled folate transporter transmembrane domain 6-7 linker. Biochem J. 2016;473:3545-62.

28. Zhao J, Li J, Fan TWM, Hou SX. Glycolytic reprogramming through PCK2 regulates tumor initiation of prostate cancer cells. Oncotarget. 2017;8:83602

29. Luo S, Li Y, Ma R, et al. Downregulation of PCK2 remodels tricarboxylic acid cycle in tumor-repopulating cells of melanoma. Oncogene. 2017;36:3609-17.

30. Liu M, Jin L, Sun S, et al. Metabolic reprogramming by PCK1 promotes TCA cataplerosis, oxidative stress and apoptosis in liver cancer cells and suppresses hepatocellular carcinoma. Oncogene. 2018;37:1637-53.

31. Leithner K, Hrzenjak A, Trötzmüller M, et al. PCK2 activation mediates an adaptive response to glucose depletion in lung cancer. Oncogene. 2015;34:1044-50.

32. Vincent EE, Sergushichev A, Griss T, et al. Mitochondrial phosphoenolpyruvate carboxykinase regulates metabolic adaptation and enables glucose-independent tumor growth. Mol Cell. 2015;60:195-207.

33. Zhang WC, Shyh-Chang N, Yang H, et al. Glycine decarboxylase activity drives non-small cell lung cancer tumor-initiating cells and tumorigenesis. Cell. 2012;148:259-72.

34. Jäger K, Larribère L, Wu H, Weiss C, Gebhardt C, Utikal J. Expression of neural crest markers GLDC and ERRFI1 is correlated with melanoma prognosis. Cancers. 2019;11:76.

35. Min HL, Kim J, Kim WH, Jang BG, Kim MA. Epigenetic silencing of the putative tumor suppressor gene GLDC (Glycine Dehydrogenase) in gastric carcinoma. Anticancer Res. 2016;36:179.

\section{Publisher's Note}

Springer Nature remains neutral with regard to jurisdictional claims in published maps and institutional affiliations.

Ready to submit your research? Choose BMC and benefit from:

- fast, convenient online submission

- thorough peer review by experienced researchers in your field

- rapid publication on acceptance

- support for research data, including large and complex data types

- gold Open Access which fosters wider collaboration and increased citations

- maximum visibility for your research: over $100 \mathrm{M}$ website views per year

At $\mathrm{BMC}$, research is always in progress.

Learn more biomedcentral.com/submissions 